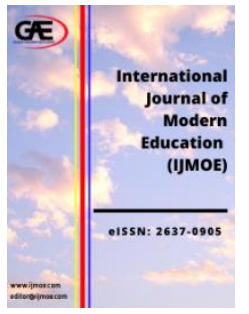

\author{
International Journal of Modern Education \\ (IJMOE) \\ Journal Website: http://ijmoe.com/ \\ eISSN: 2637-0905
}

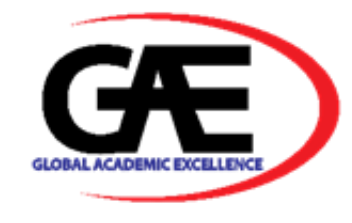

\title{
LEARNING MATHEMATICAL STATISTICS IN MASSIVE OPEN ONLINE COURSES (MOOCs)
}

\author{
Nur Faezah Jamal ${ }^{1 *}$, Nor Mariyah Abdul Ghafar ${ }^{2}$, Isma Liana Ismail ${ }^{3}$, Mohd Zaki Awang Chek ${ }^{4}$, \\ Mohd Sapuan Baharuddin ${ }^{5}$
}

1 Faculty of Computer and Mathematical Sciences, Universiti Teknologi MARA Perak Branch, Tapah Campus Malaysia

Email: nurfa210@uitm.edu.my

2 Faculty of Computer and Mathematical Sciences, Universiti Teknologi MARA Perak Branch, Tapah Campus Malaysia

Email: norma674@uitm.edu.my

3 Faculty of Computer and Mathematical Sciences, Universiti Teknologi MARA Perak Branch, Tapah Campus Malaysia

Email: isma1246@uitm.edu.my

4 Faculty of Computer and Mathematical Sciences, Universiti Teknologi MARA Perak Branch, Tapah Campus Malaysia

Email: mohdz220@uitm.edu.my

5 Faculty of Computer and Mathematical Sciences, Universiti Teknologi MARA Perak Branch, Tapah Campus Malaysia

Email: mohds026@uitm.edu.my

* Corresponding Author

\section{Article Info:}

Article history:

Received date: 27.04 .2020

Revised date: 11.06.2020

Accepted date: 14.06.2020

Published date: 15.06.2020

\section{To cite this document:}

Jamal, N. F., Ghafar, N. M. A., Ismail, I. L., Awang Chek, M. Z., \& Baharuddin, M. S. (2020). Learning Mathematical Statistics In Massive Open Online Courses (MOOCs). International Journal of Modern Education, 2(5), 38-45.

DOI: $10.35631 / \mathrm{IJMOE} .25005$

\begin{abstract}
:
E-learning using Massive Open Online Courses (MOOCs) has attracted a great deal of attention among higher education providers. The use of MOOCs is one of the great ideas supported by the Malaysia Ministry of Education in making the standard of our country's education system in line with global education. Today, there were a growing number of MOOCs that continually becoming available on commercial platforms such as Openlearning.com and MOOCs Universiti Teknologi MARA (UiTM). Like many other subjects, Mathematical Statistics is a challenging subject for teaching and learning. Certain skills in this subject require ongoing guidance on how to provide the best teaching. Hence, MOOCs for Mathematical Statistics has been created to provide knowledge and skills to teach mathematics and statistical modelling briefly, conveniently, and effectively. This study focuses on providing a general design for assessing learners who study Mathematical Statistics through MOOCs platform. The platform is developed in such a way that learners can discuss and reflect. The design of MOOCs is governed by the Guidelines for Development and Delivery of Malaysia MOOCs. With the development of this MOOCs, it is hoped that it could help learners to understand Mathematical Statistics in a more effective and efficient way.
\end{abstract}


Keywords:

Mathematical Statistics, MOOCs, Openlearning.com

\section{Introduction}

Mathematical Statistics is a subject that contains both mathematics in the form of probability theory and statistics. The term "mathematical statistics" pointed out the statistical inference of probability and mathematical theories which are used in statistical tools. Learners should describe and analyze data by the help of mathematics and statistical modelling suitable for various kind of random phenomena. For non-statistics majors, teaching probability theory and mathematical statistics have become an integral part of higher mathematics education.

Mathematical Statistics is one of the subjects that learners take in their course in Universiti Teknologi MARA (UiTM). This subject is also one of the most difficult subjects for learners. Therefore, learners need an easier way of learning. In order to assist learners in understanding this subject, they can use MOOCs as an e-learning platform (Chek, Ismail, \& Jamal, 2019). Massive Open Online Courses (MOOCs) embarked on a new era of open education that made lifelong e-learning and extensive sharing of high-quality educational resources can be implemented and received through the power of the internet. MOOCs is a platform that considered the learners have been evaluated to understand subjects in a more effective manner (Ismail, Jamal, Awang Chek, \& Baharuddin, 2019).

According to (Khalil, 2018), because they are open to everyone for free, MOOCs excel in attracting many participants which can reach hundreds and hundreds of thousands. Experts from various disciplines have shown significant interest in MOOCs because the phenomenon has evolved rapidly.

Besides that, the learner's assessment through automatic grading offered by many learning systems can also help learners to improve their existing knowledge. (Jono, M., 2013) stated that the current issues in teaching and learning are lack of space and time, all communications are not archived for future reference, communication in groups, motivate learners for selflearning, low and medium levels of learner interaction and accountability, and difficult to share ideas and responsibilities.

However, by using MOOCs, the subject can be presented in an interactive means while storing the data in one platform. As an e-learning platform, learners can also access it almost anytime and anywhere. Thus, using e-learning will reduce the learning time compared to traditional classroom. So, the main purpose of this paper is to provide a general design for assessing learners who study Mathematical Statistics through the MOOCs platform (Ridzuan, Chek, Ghafar, \& Ahmad, 2018).

\section{Significance of Study}

MOOCs can be used as a material and reference for review in line with the courses created by and offered in universities. Before entering the university, learners are given the option to view the courses offered by the university. Likewise, MOOCs enable learners to learn the courses for free. Moreover, they have an option for any courses they want to study. Generally, MOOCs can be applied to replace the traditional classroom (i-Learn Centre, 2016). 


\section{Theoretical Framework}

According to (Koper \& Tattersall ,2005), design for learning can be defined as the act of devising new practices, plans of activity, resources, and tools aimed at achieving educational goals in each situation. Strategies to guide and describe learning design have different names, such as lesson plan, course scripts, and frameworks.

In addition, (Fassbinder, A. G. O.; Fassbinder, M.; Barbosa, E. F. Francine; Magoulas, 2016) had also identified to understand how instructors are designing for learning in MOOCs, firstly, they conducted a systematic review; then, to decrease bias, they also did a data triangulation using a questionnaire with instructors who performed MOOCs.

Moreover,( Hew ,2016) found out that through the use of MOOCs; instructor is driven by a sense of intrigue, desire to get some personal rewards (egoistic), in the meantime the learners have the desire to learn about a new topic or to survey the current knowledge they were inquisitive about MOOCs, for personal challenge, and the desire to collect as many completion certificates as possible.

According to (Jisoo, Ahreum, \& Junseok ,2018) reported that it is estimated that edX, Coursera, Udacity each has 10 million, 23 million, and 4 million registered users worldwide. Apart from these three platforms, the spread and adoption of other countries has been implemented consistently. A report from (Jisoo et al., 2018), presently, MOOCs platforms that the most popular used are XueTangX, JMOOC, K-MOOC, Coursera, Khan Academy, Merlot, Udemy, FutureLearn, Iversity, OpenUpEd, Open2Study, Linda.com, pluralsight, CodeAcademy, edX, Udacity, and Miriada X (Ng, 2014) (Shuang ${ }^{\mathrm{a}}$, Azeezeen, Tengku, Thambyraja ${ }^{\mathrm{a}}$, \& Ibrahim $^{\mathrm{b}}$, 2012).

In addition, (Shah,2016) stated that MOOCs expertise in arranging statistics related to MOOCs, showing some value increase behind MOOCs. This report shows that the number of learners with experience in the MOOCs registered has increased up to 58 million worldwide, distributed among more than 7,000 courses, with more than 700 universities taking part.

Figure 1 shows, the development of MOOCs creates a perfect environment for the integration of teaching research and big data(Xi, Chen, \& Wang, 2018). The lifecycle of the big data generated from MOOCs can be described below:

a) Acquire data: Generated data are captured periodically at source, typically as part of learning operations such as viewing materials, posting, surveys, social media etc.

b) Organize: Data is transferred from various sources and consolidated into a big data platform to prepare it for processing.

c) Analyze: Data stored in the big data platform is processed using various analysis modules, either in batches or a real-time processing.

d) Optimize Learning: The results of the "Analyze" phase are presented to MOOCs' stakeholders, enabling actions. 


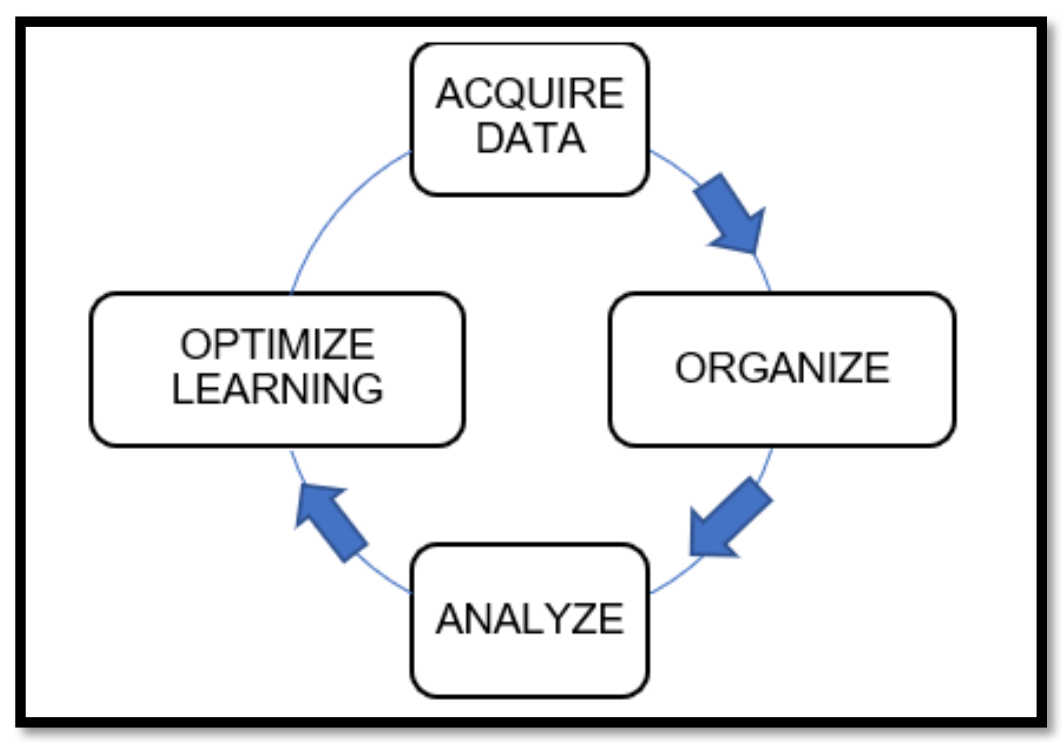

Figure 1: Development of MOOCs

According to (Ahmad, 2018), there are several reasons MOOCs platform more popular than others. Firstly, because of the MOOCs platform itself. These platforms have provided a new world of digital learning not only to the learners, but also to the course owners and Subject Matter Experts. Secondly, a differentiated pedagogy, which essentially departs from conventional eLearning pedagogy. Lastly, some of the most popular and successful MOOCs are the ones being offered by leading universities and educational institutions. While the MOOCs developed by these course providers pledge a high level of instructional and technical authority and credibility, they also promise opportunities for career advancement, unlike many conventional eLearning courses.

Hellenic Open University (HOU) could develop its own MOOCs, a comparative evaluation between different MOOC platforms was conducted. Table 1 shows, it is observed MOOC features (such as open access, freedom of pace, etc.) that although all platforms provide open courses promoting free access, the significant issue of open source is only provided by edX and Khan Academy platforms. (Tsironis \& Hellenic, 2016). For UiTM MOOCs platform develop open source educational systems through a framework of free access, freedom of pace, freedom of space and freedom of start.

Table 1: Comparing MOOCs Platforms Features

\begin{tabular}{|l|l|l|l|l|l|l|}
\hline Case & Coursera & $\begin{array}{l}\text { Khan } \\
\text { Academy }\end{array}$ & Udemy & edX & FutureLearn & Udacity \\
\hline Open access & I & $/$ & $/$ & $/$ & $/$ & / \\
\hline Free access & I & $/$ & $/$ & $/$ & $/$ & $/$ \\
\hline Freedom of pace & $/$ & $/$ & $/$ & $/$ & $/$ & $/$ \\
\hline Freedom of space & $/$ & $/$ & $/$ & $/$ & $/$ & $/$ \\
\hline Freedom of start & I & $/$ & $/$ & $/$ & - & / \\
\hline Open source & - & $/$ & - & $/$ & - & - \\
\hline
\end{tabular}

According to (Ayub, 2018), factors that affect the learners' acceptance of MOOCs are selfdirected learning environment, user friendly design of course contents, interactivity, guidance provided and fast internet speed. Learners can choose what content they wish to learn, which 
makes their learning personalized. The openness of MOOCs allows learners have free access to content, activities, and assessment.

MOOCs learning analytics there are the challenges of going beyond the logs, observing and making sense of interactions, annotations for assessment, dynamic adaptation of learning processes, the need to provide avenues for deeper learning, while managing and protecting the identity and privacy of learners(Alain, 2014). Moreover, there are also difficult issues relating to identity fraud, plagiarism, peer learning, meaningful feedback, and assessment of learning outcomes which need to be addressed going forward.(Fournier \& Kop, 2015)

\section{General Design of MOOCs}

In UiTM, learners can assess UiTM MOOCs as their platform for MOOCs. OpenLearning platform that are used by all UiTM MOOCs currently available at https://www.openlearning.com/uitm. This platform is developed in such a way that learners can discuss and reflect. Aziz, (2018) stated that the MOOCs developers are provided with tools to create a learning community.

Starting in 2019, OpenLearning platform would charge the learners or users who use the platform. UiTM has taken the initiative to develop its own MOOCs platform for free that presently available at https://ufuture.uitm.edu.my/. The design of this MOOCs is still the same as in OpenLearning platform. Despite of having freedom for developers to create their own MOOCs, the design of MOOCs is administered by the Guidelines for Development and Delivery of Malaysia MOOCs (Ministry of education, 2017).

Furthermore, all public universities should adhere to this guideline when developing MOOCs as a standard guideline. In the new platform that created by UiTM, there are two main components: a homepage and a content page. MOOCs developers are given the freedom to develop and design their courses that stated in the guidelines.

According to the Guidelines for Development and Delivery of Malaysia MOOC (Ministry of education, 2017), the first component is the homepage or landing page. This page should have an introductory video of the subject, course information, course synopsis and course learning outcomes (CLO).

The second component is the content page. The page should have a list of sub-topics, topic learning outcomes, learning materials, learning activities, assessment, and additional references. In this content page, UiTM MOOCs also added two tracking buttons. The first button is to track the activities for learners that require them to view all notes, assessment, and additional references. Whereas the second button is to track the learners to post their comments. The developer can choose to enable these tracking buttons.

UiTM MOOCs had several additional components in the homepage. These additional components were added to meet the requirements of UiTM MOOCs. The first additional component is course introductory video shows in Figure 2. This video should include course description, course learning outcomes, listing of topics and other important information according to course information. The duration of the video should not exceed 3 minutes. The second component is course information that consists detailed information about the course including the list of topics to be covered in the course, learning activities and assessment shows in Figure 3. For Mathematical Statistics subject, it consists of 4 topics which are Sampling Distributions, Estimation, Hypotheses Testing and Chi-square Test. 


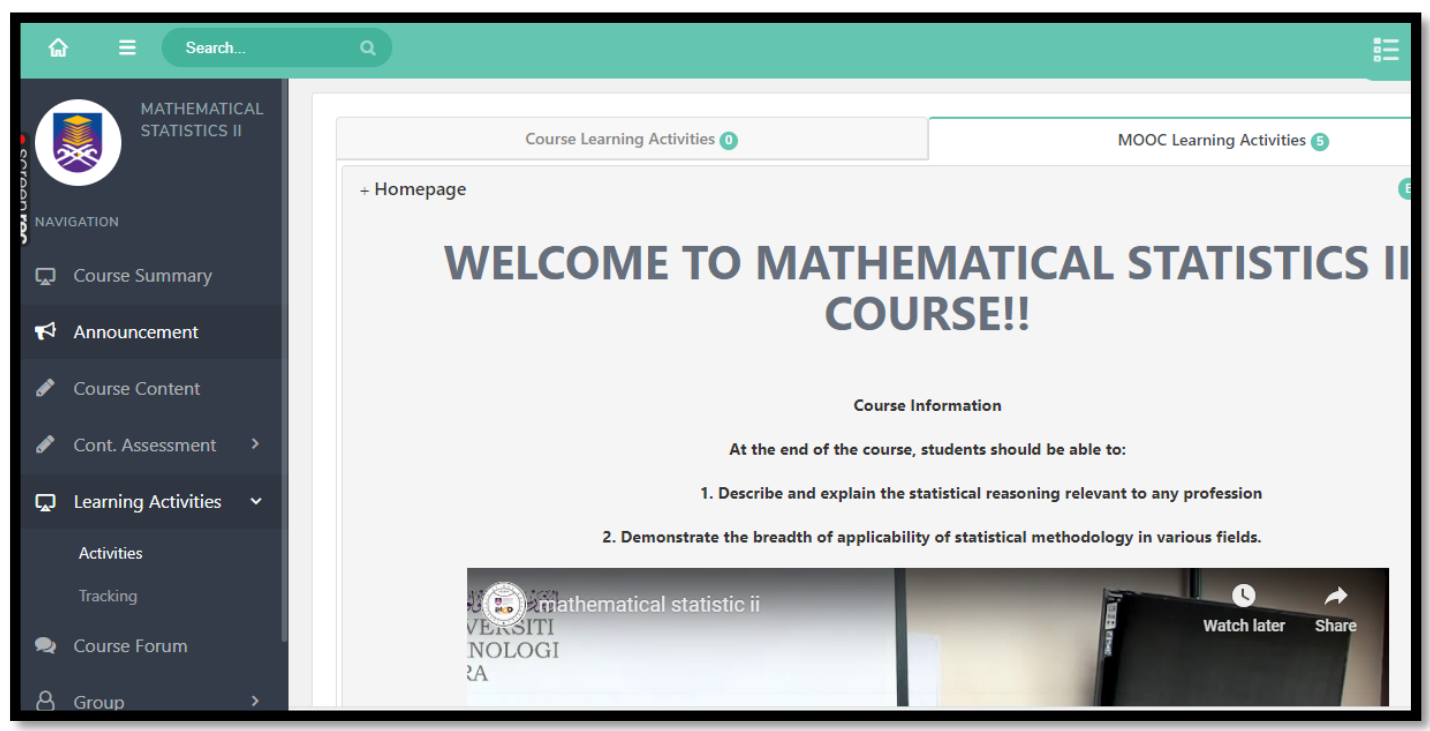

Figure 2: Homepage MOOCs Mathematical Statistics Course

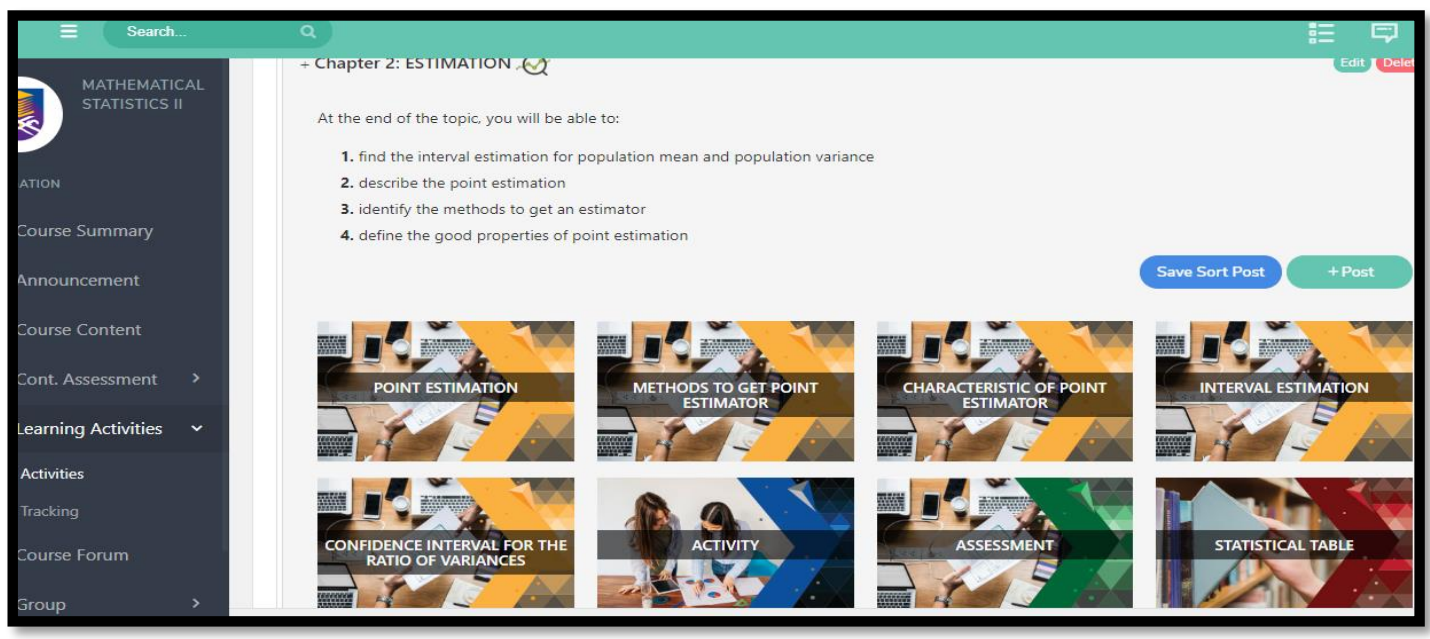

Figure 3: Activities and Evaluation of MOOCs

The third component is course synopsis that should contain between 100-200 words. This synopsis should include general information about the subject or course, delivery format and learning outcomes that learners will achieve. The fourth component is course learning outcome (CLO). The CLO must be clearly stated so that learners are aware of the skills they will acquire. For example, CLO for Mathematical Statistics are to describe and explain the statistical reasoning relevant to any profession (CLO1) and to demonstrate the breadth of applicability of statistical methodology in various fields (CLO2).

From the learners' comments and feedback, they are really liked this MOOCs because of all the notes, activity, assessment, and reference material available through this MOOCs. In addition, this MOOCs is also easy to browse anywhere as long as there is an internet line.

\section{Conclusion}

Mathematical Statistics is an interesting subject whereby the learners will be able to apply the statistical inference of probability and mathematical theories. As learners facing difficulties due to time constraint and limited face to face classroom learning, the development of MOOCs can help in making the learning process easily accessible with unlimited course resources. The 
nature of MOOCs will lead to a new dimension in technical learning and understanding feedback from learners that enabled the instructors or lecturers to make continuous improvement to all courses.

MOOCs is one of the most creative and innovative initiatives within e-learning and can also be applied to distance education that develop new learning opportunities in university education. Moreover, designing the MOOCs as training course can consider all the opportunities of the learners.

\section{References}

Ahmad, S. (2018). 3 Reasons Why MOOCs Are Popular - eLearning Industry. In eLearning Industry. Retrieved from https://elearningindustry.com/why-moocs-are-popular-3reasons

Alain, M. (2014). MOOCs: New research questions and method? Retrieved from http://prezi.com/owhcvtpwsu5q/moocs-new-research-questions-and-method/

Ayub, E. (2018). Redesigning Learning for Greater Social Impact. Redesigning Learning for Greater Social Impact, (August). https://doi.org/10.1007/978-981-10-4223-2

Aziz, A. (2018). Evaluating the Design Standard of UiTM Massive Open Online Courses. International Journal of Education and Literacy Studies, 6(4), 138. https://doi.org/10.7575/aiac.ijels.v.6n.4p.138

Chek, M. Z. A., Ismail, I. L., \& Jamal, N. F. (2019). Personal Financial Planning through Massive Open Online Course. International Journal of Academic Research in Business and Social Sciences, 9(5), 618-622. https://doi.org/10.6007/IJARBSS/v9-i5/6004

Fassbinder, A. G. O., Barbosa, E.F. and Magoulas, G. (2016). Towards a MOOC Design Model based on Flipped Learning and Patterns: A Case on Introductory Courses. XXI Conferência Internacional Sobre Informática Na Educação., 12, 130-141.

Fournier, H., \& Kop, R. (2015). MOOC learning experience design: Issues and challenges. International Journal on E-Learning: Corporate, Government, Healthcare, and Higher Education, 14(3), 289-304.

Hew, K. F. (2016). Promoting engagement in online courses: What strategies can we learn from three highly rated MOOCS. British Journal of Educational Technology, 47(2), 320-341. https://doi.org/10.1111/bjet.12235

i-Learn Centre. (2016). Garis panduan pembangunan e-kandungan kursus UiTM. https://doi.org/10.1017/CBO9781107415324.004

Ismail, I. L., Jamal, N. F., Awang Chek, M. Z., \& Baharuddin, M. S. (2019). Learning Basic Statistics and Probability Through MOOC. International Journal of Modern Trends in Social Sciences, 2(8), 99-107. https://doi.org/10.35631/ijmtss.280010

Jisoo Lee, Ahreum Hong, J. H. (2018). A Review of Massive Open Online Courses: MOOC'S approach to Bridge the Digital Divide.

Jono, M., et al. (2013). e-Materials Application Presentation Using Gagne Learning Theory for "Introduction to $\mathrm{C}++$ Computer Programming." International Conference on Education and Modern Educational Technologies E-Materials, 122-127.

Khalil, M. (2018). Learning Analytics in Massive Open Online Courses. (April). Retrieved from http://arxiv.org/abs/1802.09344

Koper, R., \& Tattersall, C. (2005). Preface. Learning Design : A Handbook on Modelling and Delivering Networked Education and Training, 2005, 1-7.

Ministry of education. (2017). Garis Panduan Pembangunan dan PenyampaiaN MOOC Malaysia. 
Ng, R. (2014). The Teaching and Learning of Mathematics Via Online : Sharing a Lifelong Learning Experience At Open University Malaysia. Seminar Kebangsaan Pembelajaran Sepanjang Hayat, 263-269.

Ridzuan, A. N. A. A., Chek, M. Z. A., Ghafar, N. M. A., \& Ahmad, A. B. (2018). Developing an Introduction to Actuarial Science MOOC. International Journal of Academic Research in Business and Social Sciences. https://doi.org/10.6007/IJARBSS/v8i1/3833

Shah, D. (2016). Monetization over Massiveness: A Review of MOOC Stats and Trends in 2016 - Class Central. 1-12. Retrieved from https://www.class-central.com/report/moocsstats-and-trends-2016/

Shuanga ${ }^{\mathrm{a}}$, G. C., Azeezeen, T., Tengku, B., Thambyraja ${ }^{\mathrm{a}}$, M. T., \& Ibrahim ${ }^{\mathrm{b}}$, Z. B. (2012). An Explotary Of Multimedia E-Learning Materials In Teaching And Learning Of Mandarin Chinese Language. (InCULT).

Tsironis, A., \& Hellenic, M. X. (2016). The implementation of MeaeX the Greek MOOC platform from Hellenic Open University 1 The need for MOOCs in Hellenic Open University 2 A comparative evaluation between different MOOC platforms. (June 2017).

Xi, J., Chen, Y., \& Wang, G. (2018). Design of a personalized massive open online course platform. International Journal of Emerging Technologies in Learning, 13(4), 58-70. https://doi.org/10.3991/ijet.v13i04.8470 